\title{
AVALIAÇÃO DE FAMÍLIAS NO CONTEXTO HOSPITALAR: UMA APROXIMAÇÃO ENTRE O MODELO CALGARY E A TAXONOMIA DA NANDA $^{1}$ \\ THE FAMILIES ASSESSMENT IN THE HOSPITAL CONTEXT: AN APPROACH BETWEEN THE CALGARY MODEL AND NANDA'S TAXONOMY \\ EVALUACIÓN DE FAMILIAS EN EL CONTEXTO HOSPITALAR: UNA APROXIMACIÓN ENTRE EL MODELO CALGARY Y LA TAXONOMÍA DE LA NANDA
}

\author{
Selma Rodrigues Alves Montefusco², Maria Márcia Bachion³, Adélia Yaeko Kyosen Nakatanit
}

\begin{abstract}
${ }^{1}$ Esta pesquisa apresenta resultados extraídos da dissertação desenvolvida junto ao Núcleo de Estudos e Pesquisas em Saúde Integral, da Faculdade de Enfermagem (FEN) da Universidade Federal de Goiás (UFG), com apoio do Conselho Nacional de Desenvolvimento Científico e Tecnológico.

${ }^{2}$ Mestranda do Programa de Mestrado em Enfermagem da FEN/UFG. Goiás, Brasil.

${ }^{3}$ Doutora em Enfermagem. Professora Titular da FEN/UFG. Orientadora da dissertação. Goiás, Brasil.

${ }^{4}$ Doutora em Enfermagem. Professora Adjunto da FEN/UFG. Goiás, Brasil.
\end{abstract}

PALAVRAS-CHAVE: Enfermagem. Família. Diagnóstico de enfermagem. Enfermagem familiar.
RESUMO: Esta pesquisa objetivou analisar os diagnósticos de enfermagem da North American Nursing Diagnosis Association (2006) identificados em famílias em situação de acompanhamento de pessoas hospitalizadas para tratamento de doenças crônicas não transmissíveis, mediante abordagem baseada no Modelo Calgary de Avaliação. Trata-se de estudo descritivo, de abordagem quanti-qualitativa, realizado na clínica médica de um hospital escola da região centro-oeste, de janeiro a junho de 2006. Foram realizadas entrevistas gravadas com 12 famílias. Os dados passaram por um processo de categorização, identificação de lacunas e divergências, agrupamento de padrões, inferência diagnóstica e determinação das relações, a partir do qual estabeleceram-se os diagnósticos. Entre as 12 categorias diagnósticas identificadas, as mais freqüentes foram: tensão devido ao papel de cuidador (100\%), comunicação verbal da família prejudicada (75\%), manutenção do lar prejudicada (66\%), processos familiares interrompidos (66\%), interação social prejudicada (25\%). Este perfil identifica áreas prioritárias de cuidado integral de enfermagem para famílias em situação de hospitalar.
KEYWORDS: Nursing. Family. Nursing diagnosis. Family nursing.

\begin{abstract}
This study aimed at assessing the nursing diagnoses of the North American Nursing Diagnosis Association (2006) identified within families accompanying patients in treatment for non-communicable chronic diseases, by using the Calgary Assessment Model. This descriptive, quantitative, qualitative study was carried out in a medical clinic at a university hospital in the Mid-western region of Brazil from January to June of 2006. Interviews with 12 families were recorded. The data was then subjected to categorization, identification of gaps and divergences, grouping of standards, diagnostic inference, and relationship determination, from which the diagnostic was established. Among the 12 identified diagnostic categories, the most frequent were: tension due to the caregiver role (100\%), impaired verbal communication from the family $(75 \%)$, impaired home maintenance management $(66 \%)$, alterations in family processes $(66 \%)$, and impaired social interactions $(25 \%)$. This profile identifies whole nursing care priority areas for those families in situations of accompanying family members in the hospital.
\end{abstract}

PALABRAS CLAVE: Enfermería. Familia. Diagnóstico de enfermería. Enfermería de la familia.
RESUMEN: El objetivo de esta investigación es el de analizar los diagnósticos de la enfermería de acuerdo con la North American Nursing Diagnosis Association (2006), los cuales fueron identificados en familias en situación de acompañamiento de personas hospitalizadas para el tratamiento de enfermedades crónicas no transmisibles, utilizando para ello el Modelo Calgary de Evaluación. Se trata de una investigación descriptiva, de carácter cuantitativo y cualitativo, realizada en la clínica médica de un hospital-escuela situado en la región centro-oeste, entre enero y junio del 2006. Para la investigación fueron realizadas entrevistas gravadas con 12 familias. Los datos recolectados pasaron por un proceso de categorización, en los que se identificaron vacíos y divergencias, agrupamiento de patrones estándares, inferencia diagnóstica y determinación de las relaciones, a partir de las cuales el diagnóstico fue establecido. Entre las 12 categorías diagnósticas identificadas, las más frecuentes fueron: tensión debido al papel de cuidador $(100 \%)$, comunicación verbal de la familia perjudicada $(75 \%)$, sustento del hogar perjudicado $(66 \%)$, relacionamientos familiares interrumpidos $(66 \%)$, interacción social perjudicada $(25 \%)$. En ese perfil se identifican áreas con prioridad de cuidado integral del sector de enfermería, para las familias en situación de acompañamiento de personas hospitalizadas.
Selma Rodrigues Alves Montefusco

Endereço: Al. Botafogo, 468

74.030-020 - Centro, Goiânia, GO, Brasil.

E-mail: sramontefusco@hotmail.com mbachion@fen.ufg.br
Artigo original: Pesquisa

Recebido em: 16 de julho de 2007 Aprovação final: 10 de janeiro de 2008 


\section{INTRODUÇÃO}

No atendimento às pessoas internadas em um hospital escola para tratamento de doenças crônicas não transmissíveis, percebemos ao longo dos anos, a presença cada vez maior da família nesse cenário, na condição de acompanhantes. A tendência observada na prática ainda é a abordagem dos familiares, e não do conjunto dinâmico e complexo que consiste na unidade familiar como foco do cuidado.

Conceituar família é uma tarefa difícil, pois há um risco de excluir formas diferenciadas de organização familiar. Podemos conceituá-la desde a forma mais tradicional, ou seja, considerando-a apenas composta do casal e seus filhos, incluindo, às vezes avós, tios e primos, até uma forma mais aberta, como a união de homossexuais.

Considera-se a família como uma unidade dinâmica constituída por pessoas que se percebem, convivem em um espaço de tempo, unidos por laços consangüíneos, laços de afetividade, de interesse e/ou doação, estruturada e organizada, com direitos e responsabilidades, vivendo em um determinado ambiente e influenciada socioeconômica e culturalmente. ${ }^{1}$ Admite-se ainda que família é quem seus membros consideram como tal. ${ }^{2}$

É necessário adotar um modelo de avaliação que contemple os fenômenos inerentes a esta unidade de cuidado, para poder compreendê-la e atendê-la também no ambiente hospitalar.

O Modelo Calgary de Avaliação e Intervenção em Família (MCAIF) envolve dois componentes: a avaliação e a intervenção na família. $\mathrm{O}$ Modelo Calgary de Avaliação de Família (MCAF) constitui uma estrutura multidimensional que possui três categorias principais: estrutural (estrutura interna, ou seja: composição da família, gênero, orientação sexual, ordem de nascimento, subsistemas e limites; estrutura externa, isto é, família extensa e sistemas mais amplos; e contexto, quer dizer, etnia, raça, classe social, religião, espiritualidade e ambiente), de desenvolvimento (estágios, tarefas e vínculos) e funcional (instrumental, que envolve as atividades de vida diária, e expressiva, que abrange a comunicação, solução de problemas, papéis, influência e poder, crenças, alianças e uniões). Nem todas as subcategorias precisam ser avaliadas e algumas nunca precisarão ser avaliadas em determinadas famílias. ${ }^{2}$

O MCAIF possui etapas que expressam as fases do Processo de Enfermagem, sendo que a etapa de avaliação no Modelo de Calgary corres- ponde às fases de coleta de dados e identificação dos diagnósticos, e a etapa de intervenção que corresponde às fases de planejamento da assistência, implementação e avaliação.

Esse modelo não adota um sistema de classificação para os diagnósticos de enfermagem, o que pode dificultar a comunicação e a comparação de resultados com outros estudos. Acreditamos que a taxonomia da North American Nursing Diagnosis Association (NANDA) é coerente com o Modelo Calgary, uma vez que nele também está previsto o julgamento clínico das respostas das famílias aos problemas reais e potenciais e aos processos vitais.

Esta aproximação foi realizada por outros estudiosos, ${ }^{3}$ no cenário de atendimento hospitalar, contudo, a abordagem recaiu sobre os familiares e não sobre a família propriamente dita.

Lidar com uma condição crônica de alteração de saúde é uma situação extremamente complexa para as famílias, provocando reações difusas. Cabe ao enfermeiro apoiá-las neste enfrentamento. ${ }^{4}$

Esta pesquisa tem o objetivo de analisar os diagnósticos de enfermagem da NANDA (2006) identificados em famílias em situação de acompanhamento de pessoas hospitalizadas para tratamento de doenças crônicas não transmissíveis, mediante abordagem baseada no Modelo Calgary de Avaliação.

Conhecer os diagnósticos de enfermagem em famílias, usando o Modelo Calgary de Avaliação, pode contribuir para criar subsídios para os profissionais se prepararem para desenvolver assistência integral, na perspectiva da abordagem do indivíduo no seu contexto de vida familiar. Os resultados desta pesquisa podem subsidiar novas pesquisas e redirecionar o ensino na área, favorecendo a integralidade e resolubilidade do cuidado, atendendo aos pressupostos do Sistema Único de Saúde.

\section{PERCURSO METODOLÓGICO}

Trata-se de um estudo descritivo, de abordagem quanti-qualitativa, que foi desenvolvido junto a 12 famílias em situação de acompanhamento de pessoas internadas em enfermarias do setor de clinica médica, em um Hospital Escola de Goiânia - GO, durante o período de janeiro a junho de 2006.

O projeto de pesquisa foi aprovado pelo Comitê de Ética em Pesquisa (protocolo 079/2005) do hospital onde foi realizado o estudo. Os parti- 
cipantes manifestaram aceite mediante assinatura do Termo de Consentimento Livre e Esclarecido.

Para coleta de dados foram realizadas entrevistas, em dois a cinco encontros, nos quais sempre estava presente a pessoa índice (o paciente), além de um ou mais familiares, mediante aplicação de um roteiro sistematizado, elaborado a partir do MCAF, ou seja, abordando-se a avaliação da estrutura (interna, externa e contextual), do desenvolvimento e do funcionamento da família. A partir destes dados elaboramos os respectivos genogramas e ecomapas. O número de encontros para a coleta de dados dependeu da disponibilidade das famílias, sendo respeitados os momentos de prestação de cuidados, de alimentação, de descanso, de avaliação pela equipe de saúde da instituição. O paciente e seus acompanhantes foram tomados como unidade, configurando-se em "famílias" participantes da pesquisa.

As entrevistas foram realizadas na própria enfermaria onde se encontravam o paciente e seu acompanhante-familiar. A decisão sobre quem estaria presente na primeira entrevista e nas subseqüentes foi determinada mutuamente pelos membros da família e pela pesquisadora que estava em campo. Em alguns casos foram abordadas duas pessoas, que representavam a família nuclear, em outros casos foram abordados três membros, de uma família de quatro ou cinco pessoas. Segundo o MCAF, não é necessário, a priori, que todos os membros estejam presentes. A enfermeira é capaz de elaborar hipóteses, avaliar o sistema familiar a partir do individuo, do casal, de uma unidade pai-filho(a), mãe-filho(a), sogro(a)-nora, enfim qualquer combinação de pessoas que se comunicam em torno de problemas de saúde compartilhados. ${ }^{2}$

Para as entrevistas, as pesquisadoras foram preparadas para o uso de categorias verbais facilitadoras da comunicação. ${ }^{5}$

As entrevistas foram gravadas com auxílio de um mini-gravador, com a permissão dos participantes. As falas transcritas serviram de base para o preenchimento do roteiro de coletas de dados.

Para identificação dos diagnósticos de enfermagem presentes na situação, foi utilizado um processo diagnóstico, ${ }^{6}$ que inclui a categorização dos dados, identificação de lacunas e dados divergentes, o agrupamento de padrões, a comparação com referências, a inferência diagnóstica e a determinação das relações. Para a rotulação dos diagnósticos foi adotada a Taxonomia II da NANDA. ${ }^{7}$
Estes procedimentos foram realizados por duas pesquisadoras, simultaneamente, examinando-se as discordâncias até obter-se consenso.

No decorrer da realização deste estudo, percebemos que alguns fenômenos não estavam adequadamente descritos na taxonomia da NANDA, ${ }^{7}$ desta forma, foram realizadas algumas modificações que estão assinaladas em negrito. Tratam-se de palavras ou expressões acrescentadas à categoria diagnóstica, fatores de risco, fatores relacionados e/ou categorias definidoras, que contribuem para o refinamento da taxonomia em sua aplicabilidade a família como unidade de cuidado.

Os diagnósticos de enfermagem foram analisados quanto à sua distribuição (freqüência simples). A discussão desses achados foi feita focalizando os títulos diagnósticos, seus fatores relacionados e características definidoras à luz do $\mathrm{MCAIF},{ }^{2}$ e da literatura científica na área de famílias.

\section{RESULTADOS E DISCUSSÃO}

Apresentaremos a caracterização das 12 famílias que participaram do estudo em relação a sua estrutura, estágio de desenvolvimento e funcionamento.

\section{Estrutura}

As famílias que participaram do estudo eram provenientes de Goiânia (cinco), de cidades do interior de Goiás (três) e outros estados (quatro), compostas, em média, de três pessoas, sendo algumas famílias intergeracionais, isto é, moravam na mesma residência, avós, filhos, netos e bisnetos. A maior parte $(80 \%)$ se constituiu a partir de dissolução de uniões ou casamentos anteriores.

A escolaridade observada nestas famílias reproduz o mapa geral de Goiás. ${ }^{8}$ Quase metade dos idosos era analfabeta e os demais apresentavam ensino fundamental incompleto. A segunda geração isto é, os filhos adultos apresentavam ensino médio completo e menos de $10 \%$ dos membros dessas famílias estavam cursando o ensino superior.

Pelos relatos, coexistiam nas famílias a aposentadoria, o desemprego, o emprego formal e informal. Em uma delas todos os membros estavam desempregados, sendo necessário o suporte de uma instituição religiosa para provisão de alimentos. Entre os aposentados e os que trabalhavam, a renda individual era de um salário mínimo. 
Havia pouca relação com outros sistemas, sendo a família extensa e a igreja os únicos vínculos externos.

\section{Desenvolvimento}

De acordo com os relatos, o ciclo de desenvolvimento das famílias nem sempre segue um curso favorável ao crescimento e desenvolvimento, em especial, a formação de vínculos, como veremos a seguir. Devido à sua estrutura, as famílias participantes desse estudo não podem ser classificadas em apenas um estágio de desenvolvimento, dentro das categorias propostas pelo MCAF. Percebe-se assim que as classificações tanto para os estágios de desenvolvimento quanto de estrutura familiar, citadas no $\mathrm{MCAF}^{2}{ }^{2}$ não conseguem descrever adequadamente as novas configurações que as famílias encontradas têm assumido.

\section{Funcional}

A pessoa índice, ou seja, o membro da família que estava hospitalizado era, na maioria das vezes, idoso (oito), vindo a seguir adultos entre 18 e 30 anos (três) e uma adolescente, com 16 anos. Os familiares acompanhantes eram todos do sexo feminino, sendo que em 10 famílias não havia revezamento de cuidadores, que eram mulheres.

Os integrantes das famílias não costumam conversar sobre sentimentos entre si. Percebemos que as algumas famílias apresentam fragilidades no funcionamento que eram anteriores ao adoecimento da pessoa índice.

A partir da coleta dos dados, utilizando o genograma e ecomapa, fizemos um "retrato" dessas famílias. A visualização destes mapas permite a identificação de forças e problemas da família, constituindo um plano de tratamento útil esquematizado. $^{2}$

\section{Diagnósticos de enfermagem identificados}

Foram encontradas, nas 12 famílias incluídas no estudo, 12 categorias diagnósticas diferentes, destacando-se repostas humanas alteradas na dimensão funcional e desenvolvimental (Tabela 1). Algumas destas respostas estavam alteradas antes da situação de internação hospitalar, e sem relação direta com o adoecimento. Outras repostas, por sua vez, estavam diretamente relacionadas à situação específica de lidar com a doença e com a internação hospitalar.

Tabela 1 - Diagnósticos de enfermagem identificados nas famílias e as categorias de avaliação do Modelo Calgary de Avaliação e Intervenção. Goiânia - GO, 2006.

\begin{tabular}{|c|c|c|c|c|c|c|c|c|c|c|c|c|c|c|}
\hline Diagnósticos de Enfermagem & $F^{* 1}$ & F2 & F3 & F4 & F5 & F6 & F7 & F8 & F9 & F10 & F11 & F12 & Total & $\%$ \\
\hline \multicolumn{15}{|l|}{ Estrutural } \\
\hline Interação social prejudicada & & & $x$ & & & & & $x$ & & & & $x$ & 3 & 25,0 \\
\hline Risco para interação social prejudicada & & & & $x$ & $x$ & & & & & & & & 2 & 16,6 \\
\hline \multicolumn{15}{|l|}{ Desenvolvimento } \\
\hline Processos familiares interrompidos & $x$ & $x$ & & $x$ & & $x$ & $x$ & $x$ & $x$ & & $x$ & & 8 & 66,0 \\
\hline Paternidade prejudicada & & $x$ & & & & & $x$ & & & & & & 2 & 16,6 \\
\hline Paternidade e maternidade prejudicada & & & & & & $x$ & & & & & & & 1 & 8,3 \\
\hline $\begin{array}{l}\text { Processos familiares disfuncionais: } \\
\text { alcoolismo }\end{array}$ & & & & & & $\mathrm{x}$ & & & & & & & 1 & 8,3 \\
\hline \multicolumn{15}{|l|}{ Funcional } \\
\hline Tensão do papel de cuidador & $x$ & $x$ & $x$ & $x$ & $x$ & $x$ & $x$ & $x$ & $x$ & $x$ & $x$ & $x$ & 12 & 100,0 \\
\hline $\begin{array}{l}\text { Comunicação verbal da família } \\
\text { prejudicada }\end{array}$ & $x$ & & $\mathrm{x}$ & & $x$ & $x$ & $x$ & $x$ & & $x$ & $x$ & $x$ & 9 & 75,0 \\
\hline Manutenção do lar prejudicado & $x$ & & $x$ & $x$ & $\mathrm{x}$ & $\mathrm{x}$ & $\mathrm{x}$ & & & $\mathrm{x}$ & $x$ & & 8 & 66,0 \\
\hline Enfrentamento familiar incapacitado & & & & & $\mathrm{x}$ & & & & & & & & 1 & 8,3 \\
\hline Risco para infecção & & & & & $\mathrm{x}$ & & & & & & & & 1 & 8,3 \\
\hline Risco para infestação & & & & & $\mathrm{x}$ & & & & & & & & 1 & 8,3 \\
\hline Total & 4 & 3 & 4 & 4 & 7 & 6 & 5 & 4 & 0 & 3 & 4 & 3 & 49 & \\
\hline
\end{tabular}


O número de diagnósticos em cada família variou de dois a sete, sendo a média de 4,1 diagnósticos por família. Dos diagnósticos identificados, 75\% são classificados como diagnóstico real, mostrando o quanto estas famílias estavam vulneráveis.

A doença é um elemento antropológico que desarticula a existência do ser doente, e de seu universo familiar emergem muitos sentimentos e percepções, entre eles a possibilidade de morte sempre presente, geradora de muito estresse e ansiedade. As famílias nesse momento existencial reorganizam-se e reforçam sua função protetora.

O diagnóstico de Tensão do papel de cuidador foi identificado em todas as famílias. ${ }^{7} \mathrm{Na}$ perspectiva do Modelo Calgary, este diagnóstico deve ser compreendido como uma resposta da família, um modo de funcionamento, numa determinada situação. O papel de cuidador nas famílias participantes do estudo era desenvolvido por mulheres - esposas, mães e filhas, que, por sua vez, reclamavam da pouca ajuda dos demais membros da família e dos amigos, levando à sobrecarga.

Por outro lado, este fato ocorreu também quando houve relutância da cuidadora em solicitar ou aceitar ajuda. Muitas vezes a cuidadora não identifica em seu círculo uma pessoa em que ele confie, e que considere como sendo tão dedicada e capaz quanto ela própria. ${ }^{9}$ Isso parece ser um enigma porque, mesmo extenuadas, algumas cuidadoras são resistentes em aceitarem o auxilio de outras pessoas para o cuidado. Essa atitude pode estar relacionada a várias causas como medo de que esse ato represente sinal de fracasso ou inadequação; medo e ansiedade em abandonar o paciente em casa, sem atendimento, tornando-se susceptível ao agravamento da doença; medo que a pessoa morra, ou ainda a super proteção e excessos de cuidados, na tentativa de minimizar sentimentos de culpa pelas ações ou negligências.

A mulher geralmente é o principal cuidador, por estar associada historicamente à responsabilidade pelos cuidados na família.,10 Torna-se difícil determinar ou diferenciar quais são as ações da mãe das de dona de casa. Essas funções são caracterizadas como femininas, estão muito interligadas. Esses cuidados que são desenvolvidos pelas mulheres, se constitui um aprendizado adquirido pela imposição sócio-cultural, que não é questionada pelas mulheres ou pelas famílias, sendo simplesmente desempenhadas. Como esse papel não foi escolhido pelas mulheres, mas sim aprendido e aceito, ele é fonte de sofrimento, desprazer e conformismo, o que prejudica a ação de cuidado. ${ }^{11}$ O impacto da carga de cuidados nos cuidadores informais tem sido extensamente estudado, ${ }^{4}$ aliado à falta de reconhecimento social. A equipe de saúde considera as ações dos cuidadores informais muitas vezes naturais, dando pouca atenção ao seu preparo técnico e suporte emocional.

O segundo diagnóstico identificado com maior freqüência foi o de Comunicação verbal da família prejudicada (nove famílias). Este diagnóstico foi modificado, pois é previsto na NANDA ${ }^{7: 54}$ para indivíduos, sendo definido como "habilidade diminuída, retardada ou ausente para receber, processar, transmitir e usar um sistema de símbolos". Entendemos a comunicação descrita pelas famílias como inadequada, sendo claramente expressa a habilidade comunicativa pouco desenvolvida, por fatores culturais, barreiras psicológicas (falta de estímulo), sendo evidenciada pela dificuldade para atingir o padrão esperado de comunicação interpessoal no contexto da família. As interações acontecem de forma superficial, principalmente devido à falta de comunicação efetiva decorrente da falta de fluidez e transparência das mesmas. Percebemos que mesmo nas famílias onde seus membros referem relacionarem-se bem, existem alguns assuntos que não são discutidos, ou são expressos na dependência de surgir um momento propício, o que muitas vezes não acontece, e as pendências ficam sem resolução. Por outro lado, a comunicação pressupõe reciprocidade e em algumas famílias estudadas isso não ocorre.

O diagnóstico de processos familiares interrompidos ${ }^{7}$ foi identificado em oito famílias e estava relacionado à alteração do estado de saúde de um membro da família, no caso, da pessoa internada. Isto teve como conseqüência troca dos papéis na família, que são expressas nas mudanças na participação dos familiares na resolução de problemas, mudança na participação na tomada de decisão e mudanças nas tarefas designadas.

Foram eventos comuns nestas famílias o novo arranjo de tarefas e papéis para lidar com a situação de doença e internação hospitalar. Algumas modificações foram mais radicais, famílias tiveram que mudar de cidade, pessoas deixaram o trabalho, abandonaram os estudos, assumiram atividades antes não designadas, para fazer frente à situação.

Em todas as famílias, independente da sociedade, cada membro ocupa determinada posição, sendo orientado por papéis. Estes papéis não são mais do que as expectativas de comportamento, de 
direitos e obrigações que estão associados a uma dada posição na família ou grupo social. ${ }^{12}$ Aos papéis atribuídos é ideal que exista flexibilidade assim como a possibilidade de troca ocasional, por exemplo, quando um dos membros não possa desempenhar o seu papel, outro membro da família assumirá a posição.

O diagnóstico de Manutenção do lar prejudicada $^{7}$ foi identificado em oito famílias. A doença do membro da família resultando na internação hospitalar, a mobilização do(s) cuidador(es) num contexto de finanças insuficientes contribuem para a organização do lar insuficiente, expressa na fala dos participantes de dificuldade para manter a sua casa de forma confortável, sobrecarga de membros da família, necessitando de ajuda. Em situações como esta a cuidadora deixa em um plano secundário os cuidados com a casa e com os demais membros da família, o que pode comprometer a manutenção do lar.

A Interação social prejudicada foi identificada em três famílias. ${ }^{7}$ Essa condição estava relacionada à ausência de pessoas do mesmo grupo etário para interagir com os membros das famílias, e mobilidade física limitada da família. Em famílias idosas que convivem com situações de agravos à saúde, sair de casa pode representar um grande desafio, fazendo com que as pessoas permaneçam quase que estritamente dentro de casa, diminuindo as oportunidades de interação social.

No geral, as famílias referem sentir falta de contato com outras pessoas, como em atividades comunitárias, confraternizações ou reuniões familiares, principalmente quando o núcleo familiar é extenso. Às vezes a instituição religiosa é o único cenário para atividade de integração social.

A família está inserida em uma rede de relações, num complexo sistema de interdependência, que é de suma importância para a sobrevivência e equilíbrio da mesma, mesmo que esta rede pareça invisível. ${ }^{13}$ Essa rede é definida como a família extensa, amigos e vizinhos, podendo se revelar fortemente atuante em praticamente todos os momentos da vida, mas se torna primordial nos momentos de crise. Percebemos que essa rede se torna mais tênue à medida que a família do doente crônico necessita usá-la por muito tempo.

Por outro lado, os cuidadores de pessoas com doenças crônicas vivenciam mudanças no estilo de vida que reduzem, modificam e geram insatisfação na vida social dos mesmos, principalmente devido às necessidades de internações recorrentes e a ida para casa com considerável carga de cuidados. Alguns fatores são limitantes à vida social do cuidador, como a sobrecarga de atividades, cuidados ao membro adoecido e tarefas de casa. ${ }^{4,9}$ Nas relações familiares podem ocorrer o aumento dos conflitos ou maior aproximação entre os membros. Os laços com a família nuclear são mantidos e até reforçados nessas situações, mas pudemos perceber que, raramente, a família extensa se envolve nos cuidados, principalmente por ser característica da doença crônica, o prolongar dos sintomas e inúmeras internações, fazendo com que a família vivencie a redução de visitas, amigos e familiares.

O diagnóstico de Risco para interação social prejudicada, não consta na NANDA como diagnóstico de enfermagem, ${ }^{7}$ mas o incluímos porque acreditamos que duas famílias com estrutura nuclear reduzida e adoecida possuíam risco de apresentarem quantidade insuficiente ou de qualidade ineficaz de troca social. Essas famílias não expressaram insatisfação com o atual padrão de iterações ou mudança no padrão mas, apresentaram fatores de risco como mobilidade física limitada (de um ou mais membros da família, que ficam predominantemente em casa, devido à precariedade da situação de saúde ou dificuldade de acesso), interação escassa com pessoas do mesmo grupo etário; ausência de pessoas do mesmo grupo etário disponíveis.

O diagnóstico de enfermagem de Processos familiares disfuncionais: alcoolismo foi encontrado em uma família, ${ }^{7}$ sendo que o fator relacionado percebido foi abuso de álcool, e as características definidoras presentes foram: dinâmica familiar alterada, desordem nos papéis familiares, negação da família (mãe), obrigações negligenciadas, habilidade ineficaz para resolução de problemas, abuso de álcool, comunicação prejudicada, dificuldade nos relacionamentos íntimos, falha em cumprir tarefas do desenvolvimento atual e vergonha.

Sabemos que o alcoolismo é uma doença que atinge não apenas o individuo, mas a família como um todo, sendo assim, não existe apenas um ser que precisa de cuidados, mas uma família. A pessoa que bebe não existe isoladamente, mas concretiza sua existência nas relações que estabelece com o mundo e com os outros seres a sua volta. ${ }^{11}$ O relacionamento social é outra área de tensão desta família, pois os familiares freqüentemente assumem certo isolamento, movidos pelo desejo de proteção do familiar ou por vergonha do estigma que cerca a doença. A pessoa que bebe e sua família têm muitos prejuízos como o afastamento 
dos amigos, perda do emprego, assim como o distanciamento ou mesmo abandono.

O diagnóstico de Enfrentamento familiar incapacitado 7 foi encontrado em uma família, estando relacionado à existência de pessoa significativa com sentimentos cronicamente não-expressos de hostilidades, estilos de enfrentamento dissonantes para lidar com tarefas adaptativas por parte da pessoa significativa; acompanhado das seguintes características definidoras: agitação, abandono, rejeição, relacionamentos negligentes com outros membros da família, cuidado negligente quanto às necessidades humanas e de tratamento da doença.

Quando a família é de idosos, existe uma dificuldade de se encontrar cuidadores, ${ }^{14}$ pois os adultos da família podem estar envolvidos com a construção de suas próprias vidas que se "esquecem" do papel de cuidador. Este fato configura-se uma perda relacional, não apenas para os idosos, mas também para o adulto que perde a oportunidade de despedir-se de seus pais retribuindo o que lhe foi dado quando criança.

Em algumas famílias observamos a retomada de ciúmes infantis em acirradas disputas entre os irmãos, que deveriam ser todos eles, cuidadores dos pais (em revezamento ou distribuição de tarefas).

A NANDA inclui em sua taxonomia o diagnóstico de Paternidade ou maternidade prejudicada, definido como "incapacidade do cuidador primário de criar, manter ou reaver um ambiente que promova o ótimo crescimento e desenvolvimento da criança". 7:101-2

Destacamos que na NANDA, o diagnóstico de Paternidade ou maternidade prejudicada focaliza famílias em estágio de desenvolvimento com filhos pequenos, ${ }^{7}$ contudo, é preciso refiná-lo para que expresse mais claramente estas condições em famílias que estão na fase de filhos adolescentes e adultos.

O diagnóstico de Paternidade e maternidade prejudicada foi identificado em uma família, que era composta por três irmãos. A pessoa índice (mulher) referiu não possuir pais, apesar de a mãe estar viva. Afirmou que a mãe abandonou a ela e seus irmãos, quando tinham seis, quatro e três anos respectivamente, após o acidente vascular cerebral do pai, há 20 anos. Em virtude da incapacidade do pai em cuidar dos filhos e devido à saída da mãe do domicilio, as crianças foram encaminhadas separadamente para diferentes tios. Mesmo que estes eventos tenham acontecido quando os filhos eram pequenos, percebemos que nesta família, persistiu a presença do diagnóstico de enfermagem Paternidade e maternidade prejudicada, de acordo com a fala dos participantes. Podemos dizer que esta condição estava relacionada a conflito matrimonial, falta de valor da maternidade, arranjos impróprios para o cuidado da criança (que agora já é adulto), presença de estresse, incapacidade dos pais de colocar as necessidades da criança a frente das suas próprias. As características definidoras identificadas foram déficit de interação pais-filhos, falta de vínculos com as crianças (que perduram até a fase adulta), e abandono (por parte da mãe).

O amor de mãe/pai é que oferece à criança condições para desenvolver o seu potencial humano, manifestar a sua maneira própria de ser. ${ }^{11}$ Os pais são os arquitetos na formação emocional dos filhos, por meio da comunicação de afeto, do cuidado amoroso e da expressão de sentimentos de segurança e confiança. Na família em que percebemos a presença deste diagnóstico, seus membros não eram crianças, mas traziam as conseqüências dessa negligência.

O diagnóstico de enfermagem de Paternidade prejudicada, foi identificado em duas famílias. Estava relacionado à conflito matrimonial, falta de valor da paternidade, arranjos impróprios para o cuidado da criança, presença de estresse, incapacidade do pai de colocar as necessidades da criança a frente das suas próprias, mudança na unidade familiar, falta de coesão da família, separação prolongada do pai, história de doença mental. As características definidoras identificadas foram declarações de incapacidade para satisfazer as necessidades de um filho, verbalização de frustração, déficit de interação pai-filha, falta de vínculo com a criança, abandono (por parte do pai).

Existe na família um compromisso e um vínculo entre os seus membros e as funções de cuidado da unidade consistem em proteção, alimentação e socialização. ${ }^{11} \mathrm{~A}$ família se realiza quando propicia condições adequadas de vida e com isso favorece o desenvolvimento das potencialidades de cada membro, principalmente através de criação e manutenção de um ambiente físico e simbólico favorável às trocas necessárias para o crescimento.

Quando o pai ou a mãe apresenta dificuldade para manter um adequado nível de crescimento e desenvolvimento dos seus filhos, estes compromissos podem não ser cumpridos, além de não serem estabelecidos o vínculo afetivo e a adequada socialização. Isto pode comprometer não só as famílias atuais como a geração de famílias futuras.

Foi identificado risco de infecção em uma das famílias, relacionado à exposição ambiental aumentada. Ao mesmo tempo, foi estabelecido o 
diagnóstico de Risco para infestação, que não faz parte dos diagnósticos descritos pela NANDA. ${ }^{7}$ A exposição ambiental em uma das famílias estava aumentada devido à presença de animais (cães), que permaneciam no mesmo ambiente que pessoas enfermas no lar, havendo presença de urina e fezes dos cachorros no interior da casa. Estes fatores podem levar tanto a infecções como a infestações.

O domicílio deve ser o produtor de saúde, ${ }^{11}$ pois nele recursos internos da família se somam aos externos, objetivando manter e restaurar a saúde de seus membros. É responsável pela proteção de seus membros incluindo a higiene pessoal, salubridade e adequação da habitação, alimentação, vestuário adequado e prevenção de acidentes no domicilio.

As famílias participantes do estudo apresentaram um conjunto de diagnósticos de enfermagem que mostra sua vulnerabilidade e necessidade de ser atendida no contexto do processo de internação hospitalar para tratamento de doença crônica não transmissível.

Embora a família sofra imensamente com o adoecimento de um de seus membros, é esperado dela que tenha forças estruturais para conter-se e apoiar o familiar doente. A maioria das famílias responde bem a essa nova contingência, mas podem ser observadas reações não cooperativas. Na maioria das famílias que assim reagem, provavelmente, já eram gravemente deterioradas as relações antes do adoecimento orgânico do familiar. ${ }^{14}$ Neste sentido, o adoecimento pode acirrar dificuldades relacionais que já estavam sendo fracamente contornadas. A internação hospitalar afeta a organização e a vida cotidiana da família em maior ou menor grau, exigindo da enfermagem sensibilidade para identificar quando seus membros requerem cuidados. ${ }^{11}$

Acreditamos que o MCAF seja um instrumento que possui grande potencial como mapa conceitual para o atendimento de famílias, pois possibilita a abordagem clínica ampliada de uma família. Este referencial permite aos profissionais identificarem as necessidades das famílias, favorecendo o planejamento das intervenções de modo mais acertado.

\section{CONCLUSÕES}

A família é uma unidade complexa com as mais diferentes necessidades, interesses, contradições e com forte influência nos comportamentos de saúde. Por isso há necessidade de aprofundar os conhecimentos sobre a unidade familiar, de elaboração ou adaptação de metodologia viável para realizar a avaliação da participação da família na atenção aos seus membros.

Mediante abordagem fundamentada no MCAF, neste estudo foram encontradas $12 \mathrm{ca}$ tegorias de diagnósticos de enfermagem, sendo $75 \%$ reais e $25 \%$ de risco. Não foram detectados diagnósticos de bem-estar. Foi identificado na maioria das famílias o diagnóstico de Tensão do papel de cuidador (100\%), Comunicação verbal familiar prejudicada $(75 \%)$, Processos familiares interrompidos e Manutenção do lar prejudicada (66\% cada).

Além disso, as interações sociais no contexto da estrutura externa das famílias revelam um panorama de poucas redes de apoio e vínculo com as instituições e com as pessoas que existem próximas aos remanescentes do núcleo familiar.

O conjunto de diagnósticos identificados revela uma situação de fragilidade e vulnerabilidade das famílias participantes do estudo, uma vez que as mesmas ainda não conseguiram adaptarse às demandas do processo de adoecimento e internação hospitalar de um de seus membros, além do próprio processo de estar em situação de acompanhamento destas pessoas.

Neste contexto, as instituições de saúde precisam estar sensíveis e desenvolver tecnologias de intervenções multiprofissionais para potencializar as forças da família como um todo. O enfermeiro não é o responsável pela adaptação ou ajuste, mas sim pela criação de um contexto para que a mudança aconteça. ${ }^{2}$

No modelo de avaliação utilizado neste estudo, o enfoque tem uma especificidade que certamente interfere na determinação dos fenômenos de interesse do profissional. Outros modelos de abordagem podem levar a diagnósticos não identificados nesta pesquisa.

\section{REFERÊNCIAS}

1 Penna CMM. Repensando o pensar: análise crítica de um referencial teórico de enfermagem à família [dissertação]. Florianópolis (SC): UFSC/PEN; 1992.

2 Wright LM; Leahey M. Enfermeiras e famílias: um guia para avaliação e intervenção na família. São Paulo (SP): Roca; 2002.

3 Goyatá SL, Rossi LA, Dalri MC. Diagnósticos de enfermagem de familiares de pacientes adultos queimados no período próximo à alta hospitalar. Rev . latino-am. Enfermagem. 2006 Jan-Fev; 14 (1): 102-9. 
4 Benjumea CC. Cuidado familiar en situaciones crônicas: una aproximación a la literatura. Texto Contexto Enferm. 2004 Jan-Mar; 13 (1): 137-46.

5 Bachion MM, Carvalho EC, Belisário VL, Cardoso AC. Algumas reflexões sobre categorias de comportamentos verbais, orais e seu emprego pela enfermagem. Cogitare Enferm. 1995 Jan-Jun; 3 (1): 113-24.

6 Risner PB. Diagnosis: analysis and synthesis of data. In: Christensen PJ, Griffith-Kenney JW. Processo de enfermagem: aplicação do Modelo Conceitual. 4a ed. St. Louis (MO/USA): Mosby; 1995. p.124-150.

7 North American Nursing Diagnosis Association, organizador. Diagnóstico de enfermagem da NANDA: definições e classificação 2005-2006. Porto Alegre (RS): Artmed; 2006.

8 Instituto Brasileiro de Geografia e Estatística Censo. 3a ed. Rio de Janeiro (RJ): IBGE; 2000.

9 Bocchi SCM, Angelo M. Interação cuidador familiarpessoa com AVC: autonomia compartilhada. Ciênc. saúde coletiva [periódico na Internet]. 2005 Set; 10 (3): 729-38 [citado 2006 Ago 10]. Disponível em: http://www.scielo.br/scielo.php?script=sci arttext\&pid=S1413-n81232005000300029\&lng=pt\& nrm=isso

10 Grandi I. Conversando com o cuidador de Alzheimer. Belém (PA): Grafisa; 1998.

11 Elsen I, Marcon SS, Silva MRS, organizadores. O viver em família e sua interface com a saúde e a doença. 2a ed. Maringá (PR): UEM; 2004.

12 Stanhope M. Teorias e desenvolvimento familiar. In: Stanhope M, Lancaster J. Enfermagem comunitária: promoção de saúde de grupos, famílias e indivíduos. 1a ed. Lisboa (PT): Lusociência; 1999. p.492-514.

13 Velho G. Subjetividade e sociedade: uma experiência de geração. Rio de Janeiro (RJ): Zahar; 1989.

14 Felício JL. As famílias de pacientes com doenças crônicas e graves: funcionamentos mais característicos. Revista Mundo Saúde, 200327 (3): 426-31. 